\title{
Espectroscopia de energia dispersiva de raios-X (EDS) acoplada ao microscópio eletrônico de varredura (MEV): fundamentos e aplicações em produtos lácteos
}

\author{
X-ray energy dispersive spectroscopy (EDS) coupled with scanning electron microscope (SEM): \\ fundamentals and applications in dairy products \\ Espectroscopia dispersiva de energía de rayos X (EDX) acoplada a microscopia electrónica de \\ barrido (MEB): fundamentos y aplicaciones en productos lácteos
}

Recebido: 23/07/2021 | Revisado: 30/07/2021 | Aceito: 05/08/2021 | Publicado: 10/08/2021

\author{
Maria Eduarda Martins Vieira \\ ORCID: https://orcid.org/0000-0001-9436-3870 \\ Universidade Federal de Juiz de Fora, Brasil \\ E-mail: eduarda@ice.ufjf.br \\ Mariana Leite Simões e Silva \\ ORCID: https://orcid.org/0000-0002-4178-3051 \\ Universidade Federal de Juiz de Fora, Brasil \\ E-mail: mariana.leite@estudante.ufjf.br \\ Luiz Fernando Cappa de Oliveira \\ ORCID: https://orcid.org/0000-0003-0595-8878 \\ Universidade Federal de Juiz de Fora, Brasil \\ E-mail: luiz.oliveira@ufjf.edu.br \\ Ítalo Tuler Perrone \\ ORCID: https://orcid.org/0000-0002-3393-4876 \\ Universidade Federal de Juiz de Fora, Brasil \\ E-mail: italotulerperrone@gmail.com \\ Rodrigo Stephani \\ ORCID: https://orcid.org/0000-0003-0237-8325 \\ Universidade Federal de Juiz de Fora, Brasil \\ E-mail: rodrigostephani@gmail.com
}

\begin{abstract}
Resumo
Devido ao aumento na procura e demanda por produtos lácteos, o estudo de suas composições químicas e das alterações que ocorrem durante o armazenamento é extremamente importante. Por isso, é necessário que se desenvolvam técnicas analíticas eficientes na investigação dos elementos constituintes de tais produtos, sendo que a espectroscopia de energia dispersiva de raios-X (EDS) acoplada ao microscópio eletrônico de varredura (MEV) é uma técnica que está se tornando mais explorada nesse âmbito. Por conta da carência de trabalhos publicados envolvendo a técnica supracitada na caracterização de produtos lácteos, este trabalho objetivou expandir o conhecimento sobre o método na área de laticínios. Na análise de amostras lácteas, o MEV fornece informações valiosas sobre a morfologia das partículas, o que é fundamental na escolha das partículas alvo. Posteriormente, através do EDS, é feita a análise elementar da superfície nas partículas alvo. Na literatura científica, observa-se a utilização do EDS acoplado ao MEV para caracterizar amostras de leite em pó, sendo relatada a predominância dos elementos carbono e oxigênio, além da presença de minerais. Ainda, as concentrações de carbono, oxigênio e nitrogênio, obtidas por meio do EDS, puderam ser aplicadas em uma fórmula matricial que permitiu o cálculo do conteúdo superficial de compostos constituintes das amostras, isto é, proteínas, lactose e gordura. Logo, pelo exposto no decorrer do trabalho, pode-se concluir que o EDS acoplado ao MEV é uma técnica de microanálise com grande potencial para ser mais explorada e utilizada na caracterização elementar da superfície de partículas que compõem amostras lácteas.
\end{abstract}

Palavras-chave: EDS; MEV; Produtos lácteos; Análise elementar.

\begin{abstract}
Due to the increase in demand for dairy products, the study of their chemical compositions and the changes that occur during storage is extremely important. Therefore, it is necessary to develop efficient analytical techniques in the investigation of the constituent elements of such products, and X-ray energy dispersive spectroscopy (EDS) coupled to the scanning electron microscope (SEM) is a technique that is becoming explored in this context. Due to the lack of published works involving the aforementioned technique in the characterization of dairy products, this work aimed to expand the knowledge about the method in the dairy area. When analyzing dairy samples, SEM provides valuable information about particle morphology, which is critical in choosing target particles. Subsequently, through EDS, the elemental analysis of the surface of the target particles is performed. In the scientific literature, the use of EDS
\end{abstract}


coupled with SEM to characterize samples of powdered milk is observed, with the predominance of the elements carbon and oxygen being reported, in addition to the presence of minerals. Still, the concentrations of carbon, oxygen and nitrogen, obtained through EDS, could be applied in a matrix formula that allowed the calculation of the surface content of constituent compounds of the samples, that is, proteins, lactose and fat. Therefore, from what was exposed in the course of the work, it can be concluded that EDS coupled to SEM is a microanalysis technique with great potential to be further explored and used in the elementary characterization of the surface of particles that make up dairy samples.

Keywords: EDS; MEV; Dairy products; Elemental analysis.

\section{Resumen}

Debido al aumento de la demanda de productos lácteos, el estudio de sus composiciones químicas y los cambios que se producen durante el almacenamiento es de suma importancia. Por lo tanto, es necesario desarrollar técnicas analíticas eficientes en la investigación de los elementos constitutivos de dichos productos, y la espectroscopia dispersiva de energía de rayos X (EDS) acoplada a microscopía electrónica de barrido (SEM) es una técnica que se está explorando en este contexto. Debido a la falta de trabajos publicados que involucren la técnica mencionada en la caracterización de productos lácteos, este trabajo tuvo como objetivo ampliar el conocimiento sobre el método en el área lechera. Analizar muestras de productos lácteos, SEM proporciona información valiosa sobre la morfología de las partículas, que es fundamental para elegir las partículas objetivo. Posteriormente, mediante EDS, se realiza el análisis elemental de la superficie de las partículas objetivo. En la literatura científica se observa el uso de EDS acoplado a SEM para caracterizar muestras de leche en polvo, reportándose el predominio de los elementos carbono y oxígeno, además de la presencia de minerales. Aún así, las concentraciones de carbono, oxígeno y nitrógeno, obtenidas mediante EDS, podrían aplicarse en una fórmula matricial que permitiera calcular el contenido superficial de los compuestos constituyentes de las muestras, es decir, proteínas, lactosa y grasa. Por lo tanto, de lo expuesto en el transcurso del trabajo, se puede concluir que el EDS acoplado a SEM es una técnica de microanálisis con gran potencial para ser explorada y utilizada en la caracterización elemental de la superficie de las partículas que componen las muestras lácteas.

Palabras clave: EDS; MEV; Productos lácteos; Análisis elemental.

\section{Introdução}

No estudo publicado por Daly et al. (2019), constatou-se que, entre os anos de 2010 e 2017, houve um aumento anual de cerca de 2,2\% na procura e demanda de leite e produtos lácteos. Aliado a essa expansão do mercado lácteo, ao comparar os anos de 2010 e 2017, verificou-se um crescimento de 16,4\% na produção de leite. Dessa forma, torna-se importante o desenvolvimento de novos métodos de análises lácteas que aliem rapidez e eficiência. Pesquisas em leite e derivados aplicam diferentes técnicas analíticas visando estudar a adequação dos produtos às legislações vigentes, atender aos atributos de qualidade esperados, bem como no desenvolvimento de novos produtos (Jesus et al., 2020; Oliveira et al., 2020; Lima et al., 2020; Manske et al., 2020; Pattaro et al., 2020; Espindola et al., 2020).

Uma das técnicas que se tornou mais explorada para o estudo de amostras lácteas, devido às suas vantagens, é o sistema de espectroscopia de energia dispersiva de raios-X (EDS, EDX ou XEDS), também conhecido como espectroscopia de análise de energia dispersiva de raios-X (EDXA) ou espectroscopia de microanálise de energia dispersiva de raios-X (EDXMA) (Ismal et al., 2019), que pode ser acoplado ao microscópio eletrônico de varredura (MEV), o qual permite a visualização da área da amostra que se deseja estudar. Esse método permite a obtenção de bons indícios acerca da composição das superfícies das partículas a serem analisadas.

O desenvolvimento da técnica de EDS só foi possível através do estudo feito pelo grupo do físico Kai Siegbahn, nas décadas de 1940 e 1950 (Siegbahn, K. et al., 1967), acerca da espectroscopia de fotoelétrons, que consiste na utilização de uma fonte de radiação eletromagnética para promover a ejeção dos elétrons da amostra. Posteriormente, a espectroscopia de energia dispersiva foi introduzida no final dos anos 60 como uma opção de técnica para análise elementar.

Uma pesquisa feita na base de dados Web of Science, correlacionando os termos EDS, energy dispersive X-ray, EDX, dairy e milk, entre os anos de 1990 e 2021, mostrou a escassez de artigos publicados englobando tais definições. A partir da busca realizada, foi possível construir um gráfico, expresso na Figura 1, demonstrando que nos 31 anos analisados, foram 
publicados, somente, cerca de 367 artigos abrangendo os 5 termos citados e combinados entre si. A pesquisa foi realizada entre 1990 e 2021, visto que só foi encontrado 1 único artigo publicado antes dos anos 90 na base de dados escolhida.

Figura 1: Número de artigos publicados entre 1990 e 2021 utilizando diferentes combinações dos termos EDS, energy dispersive $X$-ray, EDX, dairy e milk.

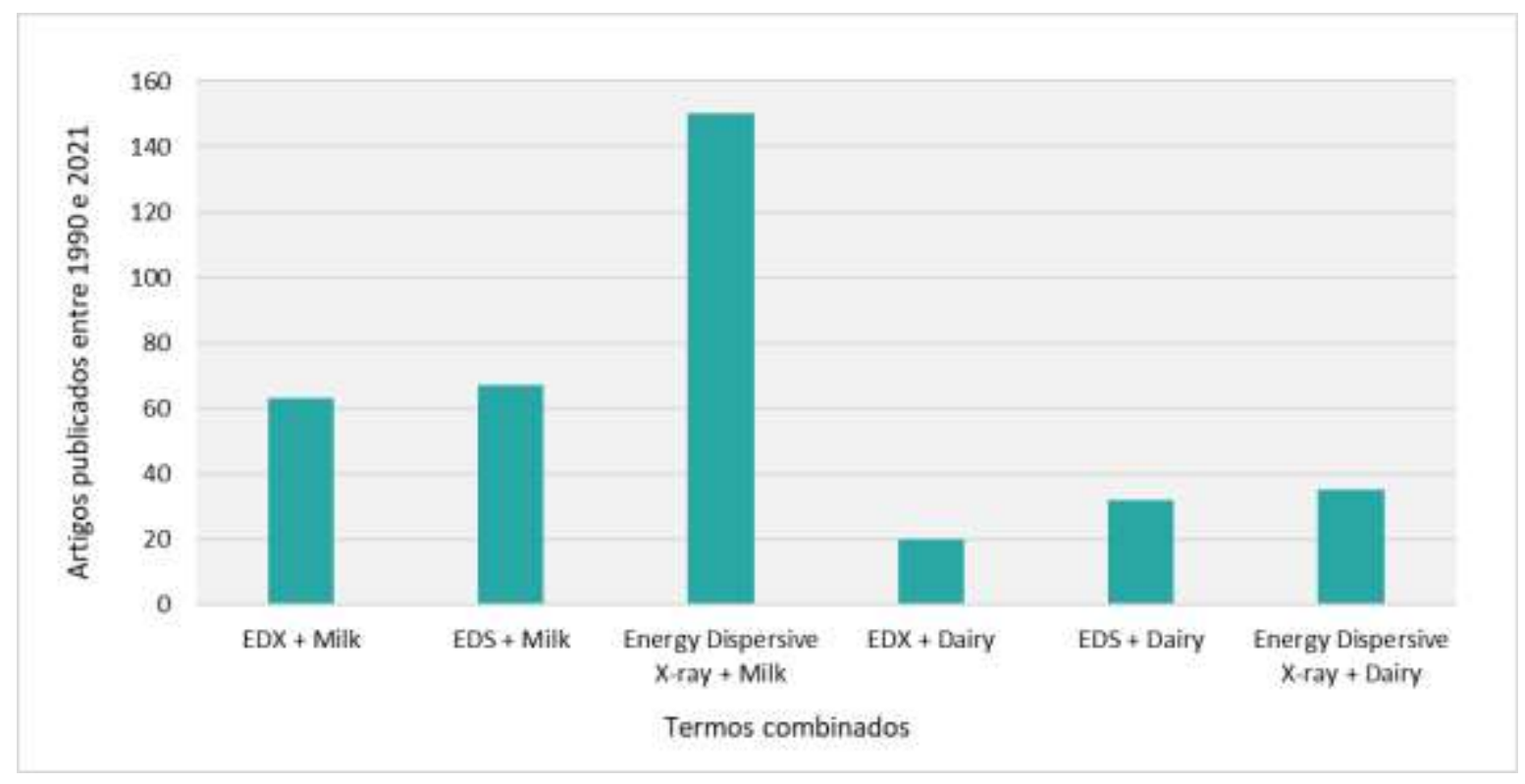

Fonte: Autores.

Devido à carência de trabalhos publicados envolvendo o uso do EDS acoplado ao MEV e sua eficiência na caracterização de produtos lácteos, este trabalho tem como objetivo expandir o conhecimento sobre a utilização do método na área de laticínios, mostrando os fundamentos básicos da técnica, bem como sua aplicação com alguns exemplos retirados da literatura.

\section{Metodologia}

O trabalho baseia-se em uma revisão narrativa por meio pesquisas de bibliografias em diferentes bases de indexação, em temas relacionados à espectroscopia de energia dispersiva de raios-X (EDS) acoplada ao microscópio eletrônico de varredura (MEV) aplicados à ciência e a tecnologia de lácteos (Pereira, et al., 2018). Buscaram-se artigos científicos adicionando as palavras-chave "espectroscopia de energia dispersiva de raios-X (EDS)", "microscópio eletrônico de varredura (MEV)", "leite", "lácteos", "leite em pó”, "proteínas lácteas", "leites fermentados”, “manteiga", "concentrados proteicos”, "leite UHT", "queijos".

Para ter a certeza de que as informações sobre o tema foram retiradas de informações confiáveis, pesquisaram-se apenas artigos científicos de bases eletrônicas de dados como: Scopus, Scielo, Science Direct, Web of Science e Wiley Online Library. Os critérios adotados para a seleção dos artigos incluíram publicações em língua inglesa e portuguesa, prioritariamente entre os anos de 2011 a 2021. 


\section{Resultados e Discussão}

\subsection{Espectroscopia por energia dispersiva de raios-X (EDS) acoplado ao microscópio eletrônico de varredura (MEV)}

O sistema de espectroscopia de energia dispersiva de raios-X (EDS) é uma técnica de microanálise que, acoplada ao microscópio eletrônico de varredura (MEV), possibilita uma alta capacidade de ampliação e visualização da amostra para análises de áreas específicas (Ferrer-Eres et al., 2010).

O MEV é um equipamento que utiliza um feixe de elétrons para explorar a superfície da amostra e, dessa forma, gerar imagens com conformação tridimensional e de alta resolução do material. Já o EDS permite a realização de uma avaliação química qualitativa e semiquantitativa, dado que sua análise se restringe à superfície da substância, não tendo precisão, mas sim, uma estimativa da concentração dos elementos presentes. Desse modo, um dos focos necessários para uma análise satisfatória é a topografia da amostra, sendo que quanto mais plano e polido for o material, melhor será o resultado semiquantitativo obtido (Duarte et al., 2003; Dedavid et al., 2007, p. 11).

\subsubsection{Funcionamento do equipamento e preparação da amostra}

O princípio de funcionamento do EDS se baseia na detecção de raios-X emitidos pela amostra durante as transições eletrônicas ocasionadas por um feixe de elétrons.

Após o material ser colocado no compartimento do MEV, um vácuo é gerado e já pode-se começar a escolher a área que será analisada. Com o início do bombardeamento de feixe de elétrons (Figura 2a), feito pela fonte do microscópio altamente energética, os elétrons presentes na camada mais interna dos átomos, que se encontram na superfície da amostra, são ejetados (Figura 2b), fazendo com que uma lacuna seja formada. Ocorre, assim, uma transição eletrônica, em que essa lacuna é preenchida por elétrons das camadas mais externas (Figura 2c), promovendo a emissão da energia de raio-X (Figura 2d), que irá equilibrar a diferença de energia entre os dois estados que o elétron percorreu. A energia de raio-X emitida, será lida pelo equipamento de acordo com a voltagem apresentada, e já que cada elétron de cada elemento químico terá a energia de emissão bem definida, o equipamento irá classificá-lo (Scoutaris et al, 2014; Goldstein et al, 2003). 
Figura 2: Esquema de uma estrutura atômica emitindo energia de raio-X devido à transição eletrônica: (a) bombardeamento de feixe de elétrons; (b) ejeção do elétron da camada interna; (c) transição eletrônica; (d) emissão de energia de raio-X característica.

a)

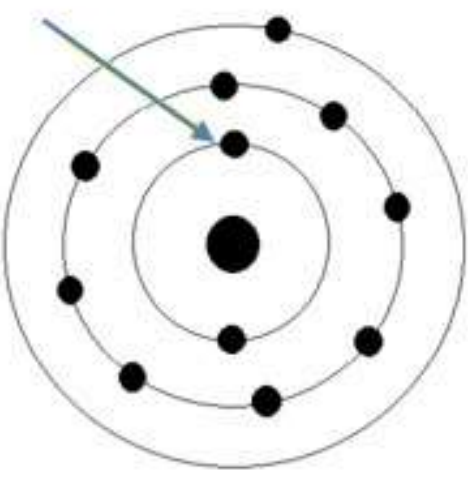

c)

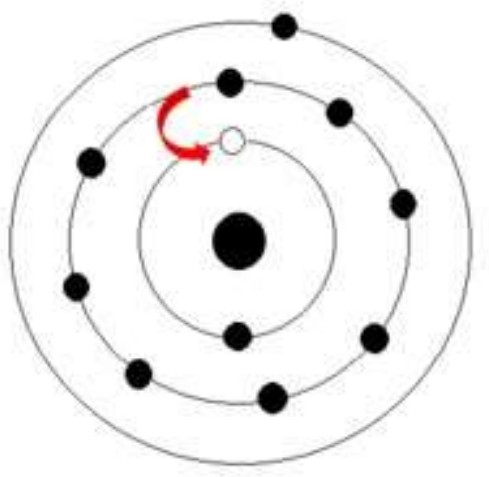

b)

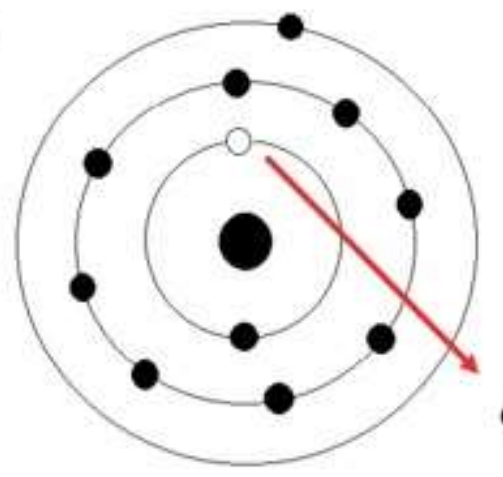

d)

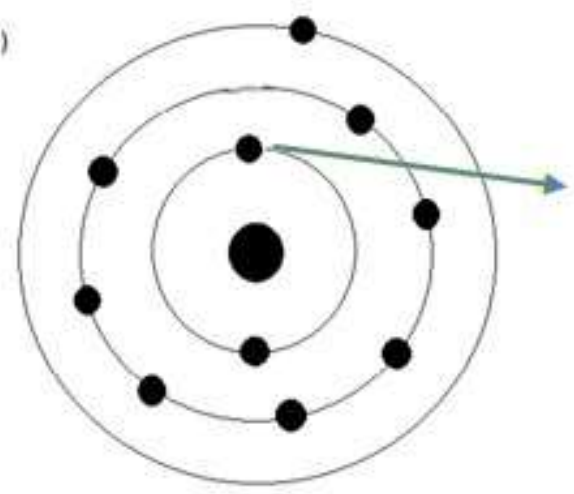

Fonte: Autores.

Assim que a voltagem emitida é lida pelo detector, um espectro de contagens de raio-X (cps/eV) vs energia (keV) é gerado (Figura 3). O eixo de contagens é referente às unidades de fótons, relativos à energia das transições eletrônicas de cada elemento químico, que atingem o detector por unidade de área. 
Figura 3: Microánalise qualitativa de elementos químicos presentes em uma amostra de cinzas de leite.

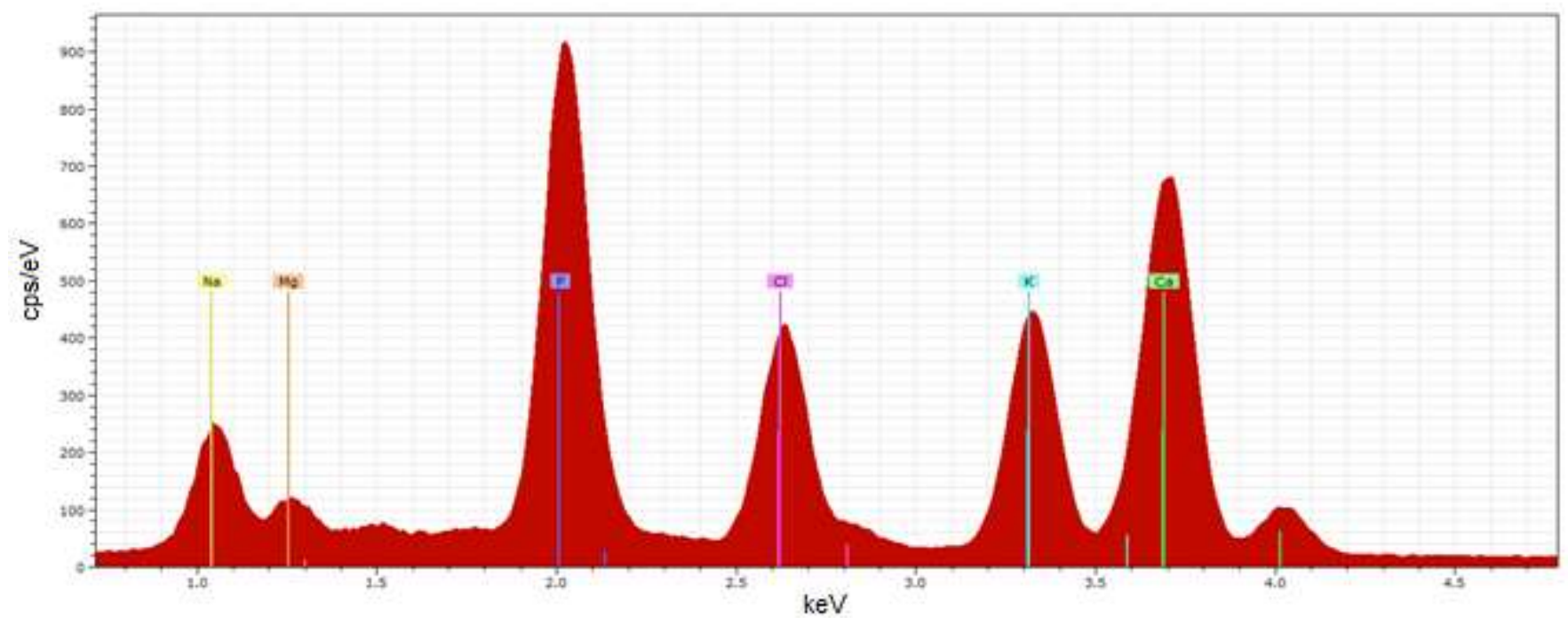

Fonte: Autores.

As duas principais exigências para a análise das amostras são: que estejam no estado sólido, devido ao vácuo gerado dentro do MEV assim que o material em análise é colocado no equipamento, e devem apresentar condutividade (Severin, 2004). Os espécimes devem ser condutores para que se mantenha um fluxo de elétrons na superfície do sistema, ou seja, os elétrons que são arrancados podem se locomover para gerar a emissão da radiação. Caso a amostra não apresente condutividade, deve-se revesti-la com uma fina camada de uma substância condutora (Parween, 2016).

\subsubsection{Vantagens e limitações da utilização do EDS}

A técnica de EDS oferece rapidez para análises qualitativas e semiquantitativas, podendo, em poucos segundos, produzir um espectro de raio-X que varia de zero a muitas dezenas de quilo elétron-volts (keV), e poderá produzir esse espectro de uma amostra de tamanho mícron, que teve apenas uma mínima preparação (Severin, 2004). Além disso, quando comparado com a técnica de espectroscopia de fotoelétrons excitados por raio-X (XPS), o EDS, ao contrário desse, permite uma caracterização da superfície em um nível mais profundo, desde o primeiro mícron até os cinco primeiros mícrons. Ademais, o EDS permite uma caracterização muito localizada na partícula, enquanto que a área de análise do XPS é maior (300 x 700m) (Murrieta-Pazos et al., 2012; Murrieta-Pazos et al., 2013).

Em contraste, existem limitações a este método, dentre as quais deve-se incluir sua baixa sensibilidade a oligoelementos e elementos mais leves que o Na. Além disso, a perda de elementos voláteis (Na) durante a excitação é um fenômeno bem conhecido (Kursula, 2000). Como o método de espectroscopia por comprimento de onda dispersivo (WDS) é mais preciso e capaz de detectar abundâncias elementares mais baixas, o EDS é menos comumente usado para análises químicas reais, embora as melhorias na resolução do detector tornem o EDS uma alternativa confiável e precisa (Materials Evaluation and Engineering, Inc., 2016).

\subsection{Uso do EDS acoplado ao MEV para a análise de produtos lácteos}

No que diz respeito às aplicações do EDS acoplado ao MEV, essa técnica analítica está sendo utilizada para investigar a superfície de produtos lácteos desidratados como, por exemplo, leite em pó. O leite é composto por uma mistura complexa de lipídeos, proteínas, carboidratos, vitaminas e minerais. Durante o processo de secagem, esses componentes do leite que eram 
distribuídos de forma uniforme pela solução são redistribuídos, o que gera uma diferença entre a superfície e o núcleo das partículas. As variações na distribuição superficial dos constituintes do leite podem afetar o produto desidratado quanto à composição, microestrutura, ao estado de aglomeração e às propriedades em geral. Por isso, torna-se importante o controle de qualidade dos produtos lácteos desidratados, o que pode ser feito com o auxílio de técnicas como o EDS e o MEV (Kim et al., 2009; Damodaran et al., 2010; Murrieta-Pazos et al., 2013; Toledo et al., 2020).

Em trabalhos apresentados na literatura científica, como no estudo feito por Murrieta-Pazos et al. (2013), foram realizadas caracterizações de amostras de leite em pó integral e desnatado por meio de EDS acoplado ao MEV (ESEM Philips XL30). Anteriormente a esse estudo, poucos autores haviam utilizado o EDS juntamente ao MEV para investigar a composição química de produtos lácteos em pó. Por conta disso, além dos leites em pó, os autores analisaram os componentes isolados do leite (caseína, proteínas do soro de leite, lactose monoidratada e gordura anidra do leite) para validar a metodologia empreg ada no trabalho. Ainda, as concentrações atômicas relativas de carbono, oxigênio e nitrogênio na superfície $(\sim 5 \mu \mathrm{m})$ dos pós foram quantificadas por meio do EDS e, com isso, os valores obtidos foram utilizados em uma fórmula de matriz, apresentada a seguir, para calcular o conteúdo superficial relativo dos diferentes compostos que constituem as amostras, isto é, proteínas (P), lactose (L) e gordura (G) (Murrieta-Pazos et al., 2012; Murrieta-Pazos et al., 2013).

$$
\begin{aligned}
& \mathrm{I}^{\mathrm{C}}=\alpha \mathrm{P} . \mathrm{I}^{\mathrm{CP}}+\alpha \mathrm{L} . \mathrm{I}^{\mathrm{CL}}+\alpha \mathrm{G} \cdot \mathrm{I}^{\mathrm{CG}} \\
& \mathrm{I}^{\mathrm{O}}=\alpha \mathrm{P} . \mathrm{I}^{\mathrm{OP}}+\alpha \mathrm{L} . \mathrm{I}^{\mathrm{OL}}+\alpha^{\prime \prime} \mathrm{G} . \mathrm{I}^{\mathrm{OG}} \\
& \mathrm{I}^{\mathrm{N}}=\alpha \mathrm{P} . \mathrm{I}^{\mathrm{NP}}+\alpha \mathrm{L} . \mathrm{I}^{\mathrm{NL}}+\alpha \mathrm{G} \cdot \mathrm{I}^{\mathrm{NG}}
\end{aligned}
$$

Nas equações (1), (2) e (3), $\mathrm{I}^{\mathrm{C}}, \mathrm{I}^{\mathrm{O}}$ e $\mathrm{I}^{\mathrm{N}}$ são as frações molares de carbono, oxigênio e nitrogênio na superfície da amostra, obtidas pela análise de EDS; $\mathrm{I}^{\mathrm{CP}}, \mathrm{I}^{\mathrm{CL}}$ e $\mathrm{I}^{\mathrm{CG}}$ são as porcentagens teóricas de carbono nas proteínas, na lactose e na gordura; $\mathrm{I}^{\mathrm{OP}}, \mathrm{I}^{\mathrm{OL}}, \mathrm{I}^{\mathrm{OG}}$ são as porcentagens teóricas de oxigênio nas proteínas, na lactose e na gordura; $\mathrm{I}^{\mathrm{NP}}, \mathrm{I}^{\mathrm{NL}}, \mathrm{I}^{\mathrm{NG}}$ são as porcentagens teóricas de nitrogênio nas proteínas, na lactose e na gordura. Os valores teóricos utilizados nas equações foram retirados da composição teórica de lactose (C: 50, O: 50), proteínas (C: 65, O: 19, N: 16) e gordura (C: 89,1, O: 10,9). Assim, resolvendo o sistema de três equações, pode-se determinar os teores de proteínas $(\alpha \mathrm{P})$, lactose $\left(\alpha\right.$ 'L) e gordura $\left(\alpha^{\prime \prime} \mathrm{G}\right)$ na superfície das amostras (Murrieta-Pazos et al., 2012).

Como resultados das análises dos componentes isolados do leite feitas por Murrieta-Pazos et al. (2013), no que tange ao MEV, foram observados pós parcialmente aglomerados nas amostras de caseína micelar. Já no caso do isolado proteico do soro de leite, foram observadas estruturas quase esféricas e individuais e, em comparação à caseína micelar, notou-se uma maior heterogeneidade no tamanho das partículas. $\mathrm{Na}$ análise da lactose, estruturas menos esféricas e mais irregulares do que as partículas de caseína e de proteínas do soro foram observadas, além de ter sido constatada a presença de pequenos cristais na superfície. Já na análise da gordura anidra do leite, uma gota de gordura fundida foi colocada no suporte e, visto que a temperatura na câmara estava próxima de $5^{\circ} \mathrm{C}$, foi formado um filme sólido.

Ainda com relação às análises dos componentes isolados do leite, foram relatadas as composições atômicas obtidas pelo EDS. No isolado proteico do soro de leite, foram detectados, além dos elementos carbono e oxigênio, nitrogênio e minerais. A presença de nitrogênio era esperada, visto que se tratavam de proteínas em pó. Nesse aspecto, vale ressaltar que, no leite em pó, as proteínas são as únicas moléculas que podem conter o elemento nitrogênio em sua composição. Já na análise da caseína micelar, foram identificados os elementos carbono, oxigênio e nitrogênio, além de maior quantidade de minerais em comparação ao isolado proteico do soro, visto que a caseína micelar contém maior teor de cálcio e fósforo. Para a lactose, que é uma molécula de carboidrato, apenas os elementos carbono e oxigênio foram encontrados, conforme o esperado. Finalmente, 
na análise da gordura anidra do leite, detectaram-se apenas os elementos carbono e oxigênio, sendo que a concentração atômica de carbono foi muito alta. Tais resultados corresponderam à composição atômica teórica da gordura anidra do leite.

As análises supracitadas, feitas com os constituintes do leite isolados, confirmam a eficácia da técnica de EDS para detectar os elementos que realmente constituem as partículas orgânicas. No entanto, observou-se uma superestimativa do teor de carbono na lactose, sendo que as razões de concentração atômica (C:79,2 e O:20,0) não ficaram de acordo com os valores estequiométricos esperados (C:50 e O:50). Essa superestimação do carbono é comum ao usar técnicas de raios-X e isso pode ter ocorrido por uma contaminação de carbono, por conta de impurezas do ar durante a transferência da amostra para a câmara do EDS ou durante a fabricação do produto. Apesar disso, o desvio padrão não variou significativamente, o que indica uma boa reprodutibilidade dos resultados para uma determinada partícula.

Após a validação da metodologia no estudo feito por Murrieta-Pazos et al. (2013), o EDS acoplado ao MEV foi utilizado para analisar a superfície e o núcleo das amostras de leite em pó integral e desnatado. Visto que a análise funciona em uma profundidade de, aproximadamente, 1 a $5 \mu \mathrm{m}$, o diâmetro da partícula pode influenciar nos resultados da análise. Por conta disso, os pós foram peneirados em cinco frações diferentes, com o objetivo de manter uma profundidade padrão de análise. Ademais, foram determinadas as porcentagens dos principais componentes (proteína, lactose e gordura) presentes na superfície dos pós com o auxílio da fórmula de matriz, isto é, pelo sistema de equações (1, 2 e 3) substituído com as porcentagens atômicas de carbono, oxigênio e nitrogênio, obtidas por EDS. Como resultados, foi observado que, para as cinco frações analisadas do leite em pó integral e para as cinco frações analisadas do leite em pó desnatado, as diferenças entre a superfície e o núcleo das partículas não foram significativas. Isso pode ser explicado pelo fato de que o EDS possibilita a caracterização da superfície das partículas em um nível profundo (1 a $5 \mu \mathrm{m})$ e, por conta disso, a análise da superfície por EDS pode ser equivalente ou muito próxima da análise do núcleo por EDS.

Finalmente, como conclusões do estudo realizado por Murrieta-Pazos et al. (2013), pôde-se constatar que a técnica de EDS acoplada ao MEV é uma boa escolha para o estudo da estrutura do leite em pó, visto que apresenta a vantagem de permitir a observação da amostra antes de se fazer a análise, ou seja, é possível focalizar a análise em uma zona de interesse (glóbulo de gordura, lactose cristalizada, etc) graças ao microscópio. No entanto, o EDS apresentou alguns problemas com relação à repetibilidade, os quais são inerentes à técnica, pois as zonas analisadas são muito pequenas e a profundidade da análise é considerável. Por conta disso, dependendo de qual for a localização da zona de análise, resultados diferentes podem ser obtidos. Apesar desse inconveniente, ao analisar um grande número de partículas em diferentes zonas, é possível melhorar a repetibilidade.

Em um outro estudo, desenvolvido por Pereira et al. (2020), foram analisados produtos originados da desidratação do leite e do soro de leite (leite em pó integral, creme de leite em pó, leite em pó desnatado, soro em pó parcialmente desmineralizado, concentrado proteico de leite e concentrado proteico de soro). Assim, o MEV acoplado ao EDS (Hitachi TM 3000) foi utilizado para realizar o mapeamento de partículas de interesse nas amostras supracitadas, objetivando gerar informações relevantes sobre a composição das superfícies.

A utilização do MEV, no trabalho desenvolvido por Pereira et al. (2020), possibilitou a identificação das partículas alvo das amostras, o que foi importante para a posterior obtenção do perfil espectral das partículas de interesse. Através das imagens obtidas pelo MEV, os autores observaram que as partículas analisadas apresentaram morfologias, tamanhos e aspectos de superfícies diferentes. As partículas de leite em pó integral e desnatado se apresentaram individualizadas, o que indica que os produtos não obtiveram aglomeração significativa durante a secagem, o que é comum em equipamentos de secagem de um único estágio. Já as partículas do concentrado proteico de leite apresentaram invaginações, as quais podem ter sido formadas pela desidratação da partícula rica em caseína. Ademais, as partículas de creme de leite em pó estavam aglomeradas, o que pode indicar que o produto foi fabricado em um equipamento de secagem de múltiplos estágios ou, ainda, que estariam 
acontecendo interações entre os lipídeos da superfície das partículas. No que diz respeito ao concentrado proteico de soro, observou-se que as partículas apresentaram regiões murchas, isto é, as partículas não estavam túrgidas. Finalmente, na análise do soro em pó parcialmente desmineralizado, foram observadas partículas com a forma de "Tomahawk", que é característica do cristal de lactose.

Com relação à constituição da superfície das partículas alvo, obtidas através do EDS no trabalho desenvolvido por Pereira et al. (2020), foi relatada a predominância dos elementos carbono e oxigênio, o que era previsto por se tratarem de compostos alimentícios. Além disso, também foi observada a presença de minerais, como cálcio, fósforo e potássio. Ainda, foram encontrados elementos atípicos à composição das amostras alimentícias analisadas, como, por exemplo, alumínio e silício. A presença de alumínio pode ser associada, provavelmente, à manipulação industrial que foi realizada para a fabricação e para o envase dos produtos. Já a presença de silício foi identificada na amostra de creme de leite em pó, devido à aspersão de dióxido de silício no produto após a secagem (o dióxido de silício possui função antiaglutinante durante a estocagem).

Desse modo, a partir dos resultados obtidos no estudo publicado por Pereira et al. (2020), os autores puderam concluir que o MEV foi importante para fornecer informações valiosas acerca da morfologia das partículas, o que foi fundamental na escolha das partículas alvo. Assim, pôde-se realizar, por meio do EDS, a determinação semiquantitativa dos elementos químicos presentes na superfície das partículas alvo.

Além dos trabalhos citados, é possível encontrar, na literatura científica, outras pesquisas que envolvem a aplicação do EDS acoplado ao MEV para a análise de produtos lácteos, com diferentes objetivos. No estudo realizado por Deng et al. (2015), por exemplo, houve a produção de leite fermentado por Lactobacillus brevis enriquecido com selênio elementar. O selênio é um oligoelemento com variadas funções biológicas importantes, porém sua aplicação é limitada devido à toxicidade que apresenta ao organismo humano. Nesse aspecto, o selênio elementar apresenta vantagens por conta de sua alta biodisponibilidade e baixa toxicidade, o que o torna viável para ser utilizado no desenvolvimento de produtos lácteos funcionais como, por exemplo, o leite fermentado. Ademais, sabe-se que, acima de uma determinada concentração, os Lactobacillus podem transformar o selenito em selênio elementar. Logo, neste trabalho, o leite foi fermentado por uma cultura iniciadora (contendo Streptococcus thermophilus e Lactobacillus bulgaricus) e pelos Lactobacillus brevis enriquecidos com selenito de sódio. Assim sendo, era esperado que os Lactobacillus brevis reduzissem o selenito tóxico a sua forma menos tóxica, que corresponde ao selênio elementar.

Nesse sentido, no trabalho desenvolvido por Deng et al. (2015), a utilização do EDS (Horiba EX-250) acoplado ao MEV (Hitachi S-4800) foi importante para analisar as partículas presentes no leite co-fermentado por Lactobacillus brevis enriquecido com selenito, de modo que fosse possível verificar a presença de selênio elementar nesse produto lácteo. Como resultados das análises realizadas pelo MEV, uma série de nanoesferas com tamanhos entre $20 \mathrm{~nm}$ e $200 \mathrm{~nm}$ foi visualizada no leite fermentado. No entanto, a partir da análise por EDS, foi observado que essas nanoesferas não geraram espectros com picos de energia correspondentes ao selênio elementar e, por isso, foram identificadas como sendo proteínas abundantes no leite, como a caseína. Ademais, através do MEV, foram observados depósitos de nanopartículas ao redor das células bacterianas no leite fermentado. Visto que o espectro gerado pelo EDS para essa área indicou um pico característico que corresponde ao selênio elementar (próximo a 1,37 keV), os autores puderam confirmar que os Lactobacillus brevis reduziram o selenito de sódio a selênio elementar (Deng et al., 2015).

Já em um trabalho desenvolvido por Gandhi et al. (2017), objetivou-se compreender o efeito da solubilidade do concentrado proteico do leite (MPC80) sobre sua suscetibilidade em iniciar a incrustação em superfícies de aço inoxidável durante o processamento térmico. Visto que a incrustação resulta em custos que incluem limpeza do equipamento, perda de produção, consumo adicional de energia e outros, é importante compreender a suscetibilidade de determinados produtos à incrustação como, por exemplo, o concentrado proteico do leite, o qual é obtido pela remoção parcial da lactose e dos minerais 
do leite desnatado. Ainda, sabe-se que a solubilidade de produtos lácteos em pó com alto teor de proteína, como o MPC80, diminui significativamente após o armazenamento em altas temperaturas, o que afeta o comportamento desses produtos no que diz respeito a incrustação em superfícies. Nesse sentido, visto que neste estudo o objetivo era compreender a influência da solubilidade do MPC80 na formação de uma camada de incrustação sobre superfícies de aço inoxidável, as amostras do concentrado proteico reconstituído em água foram armazenadas a $25^{\circ} \mathrm{Ce} 40^{\circ} \mathrm{C}$.

Assim, no estudo feito por Gandhi et al. (2017), o EDS acoplado ao MEV (FEI Versa 3D DualBeam) auxiliou no estudo da composição, da microestrutura e da distribuição espacial de elementos químicos ao longo da camada de incrustação formada sobre um trocador de calor de placas (ocasionada pelo MPC80 reconstituído em água). As análises realizadas pelo MEV revelaram a heterogeneidade e a espessura desuniforme da camada de incrustação, além da distribuição de lipídeos, proteínas e cálcio na superfície da mesma. Ainda, através do MEV, observou-se que as camadas de incrustação formadas pelo MPC80 pouco solúvel (armazenado a $40^{\circ} \mathrm{C}$ ) eram mais espessas do que aquelas formadas pelo MPC80 mais solúvel (armazenado a $25^{\circ} \mathrm{C}$ ). Já a análise da composição elementar das camadas incrustadas, feita por meio do EDS, demonstrou que carbono, oxigênio, nitrogênio e cálcio foram os principais elementos constituintes da incrustação formada pelo MPC80 menos e mais solúvel. Além disso, uma pequena porcentagem de enxofre e fósforo foi relatada. Nesse sentido, pôde-se associar a presença de carbono e oxigênio com a presença de lipídios, enquanto a presença de carbono e nitrogênio foi associada a presença de proteínas na camada de incrustação. A presença de uma pequena quantidade de enxofre pode indicar a presença de aminoácidos contendo esse elemento químico. Ademais, o mapeamento dos elementos mostrou que o nitrogênio, associado a presença de proteínas, estava presente em um ponto específico, enquanto o cálcio estava distribuído por toda a camada de incrustação.

Com estes resultados, concluiu-se que as análises realizadas pelo EDS acoplado ao MEV foram essenciais na compreensão da composição e da estrutura das camadas de incrustação, bem como no entendimento de que a menor solubilidade do MPC80 gera maiores quantidades de incrustação. Assim, as informações adquiridas através de ambas as técnicas acopladas podem ser utilizadas para otimizar as condições de processamento e desenvolver estratégias de limpeza das superfícies que sejam eficazes (Gandhi et al., 2017).

Ainda no que diz respeito à utilização do MEV acoplado ao EDS para a análise de produtos lácteos, trabalhos nesse âmbito vêm sendo desenvolvidos no laboratório de Química e Tecnologia, pertencente ao Núcleo de Espectroscopia de Estrutura Molecular da Universidade Federal de Juiz de Fora. Nesse sentido, alguns resultados de análises que foram realizadas com uma amostra de leite em pó de búfala podem ser observados nas Figuras 4 e 5 . A Figura 4, que representa uma imagem obtida por MEV da amostra de leite de búfala em pó, permite a visualização da morfologia, do tamanho e dos aspectos da superfície das partículas presentes na amostra, além de ser possível observar a aglomeração das partículas, o que influencia a solubilidade do leite em pó (Toledo et al., 2020). Já a Figura 5 expressa os resultados da composição da superfície das partículas presentes na amostra de leite em pó de búfala, os quais foram obtidos por meio do EDS. No espectro apresentado na Figura 5, pode-se observar que a amostra analisada possui predomínio do elemento oxigênio e, além disso, destacam-se os minerais cálcio, fósforo e potássio. 
Figura 4. Micrografia de uma amostra de leite em pó de búfala com ampliação de 1500x.

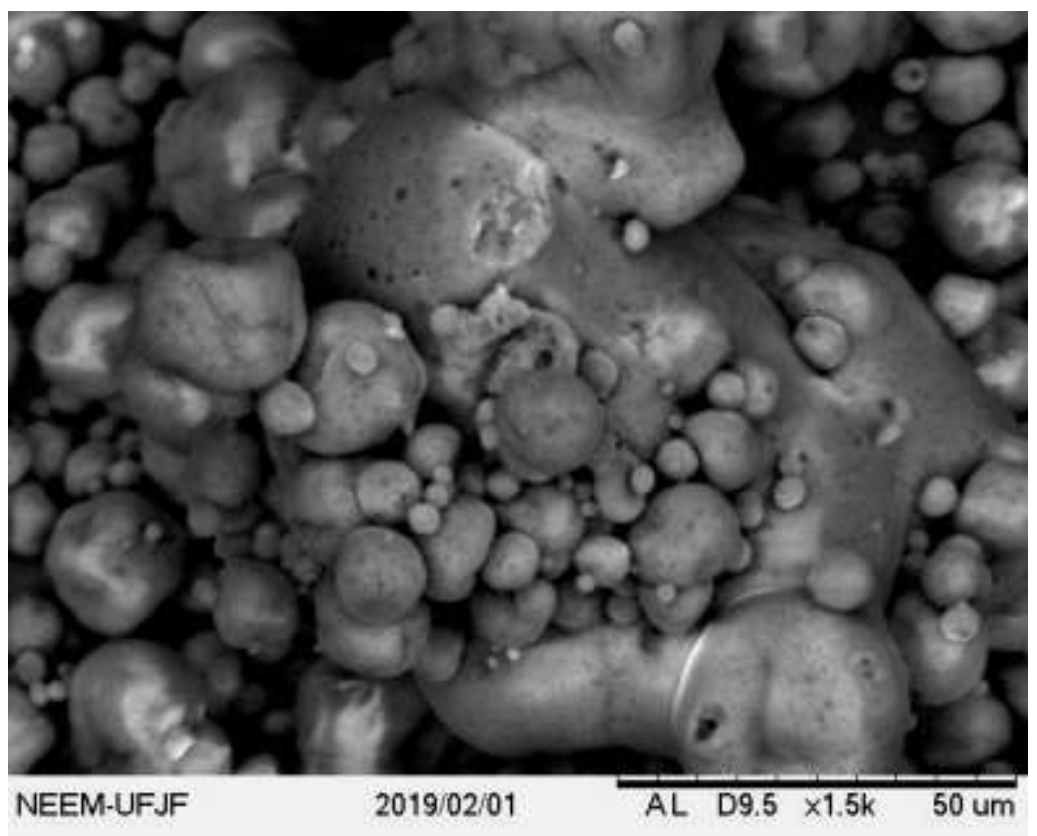

Fonte: Autores.

Figura 5. Microanálise qualitativa de elementos químicos presentes em uma amostra de leite em pó de búfala.

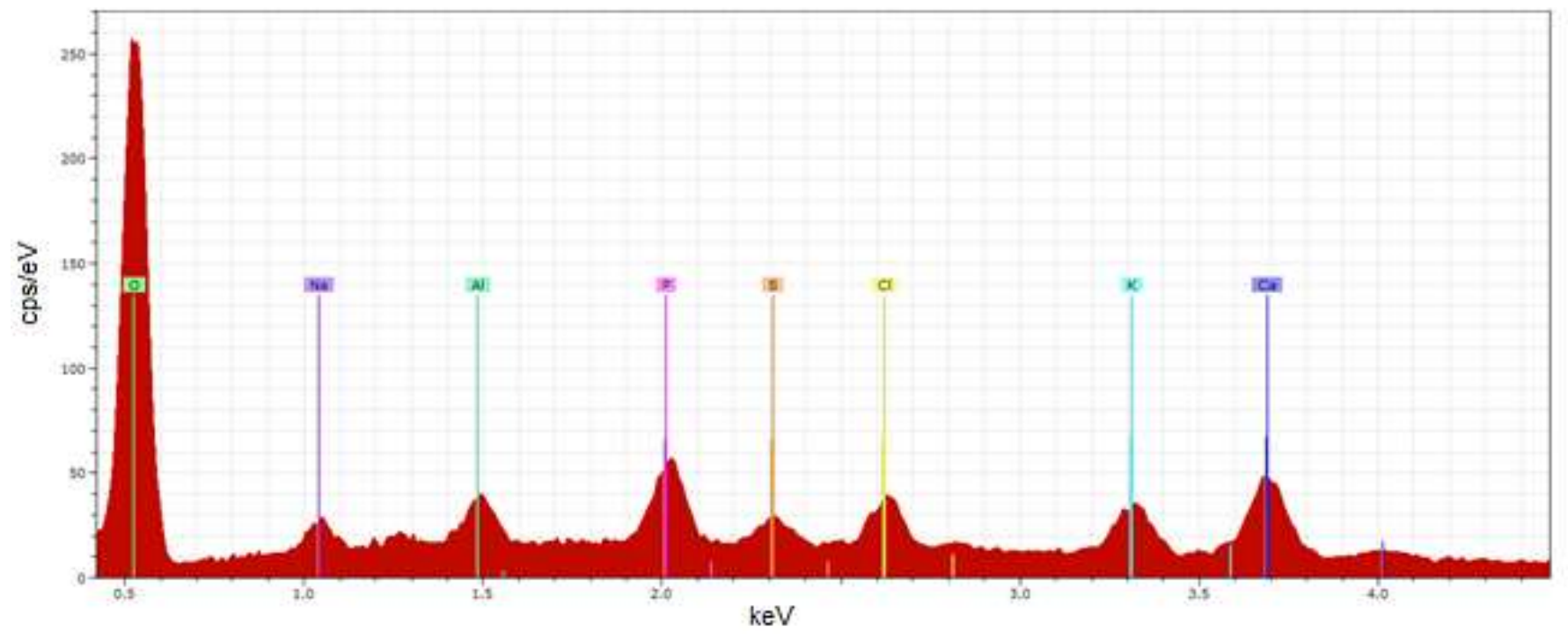

Fonte: Autores.

\section{Considerações Finais}

Pelo exposto no decorrer deste artigo parece-nos inegável o crescimento constante do mercado de laticínios e, tendo em vista essa expansão, é urgente que métodos que associem eficiência e qualidade em suas análises sejam otimizados para a caracterização de produtos lácteos. Nesse sentido, o sistema de espectroscopia de energia dispersiva de raios-X, acoplado ao microscópio eletrônico de varredura, apresenta-se como uma alternativa viável, considerando sua rapidez e capacidade de análise. Portanto, devido a essas características, o método se mostra apto a ser mais explorado nos estudos de produtos do setor de laticínios. Trabalhos futuros de pesquisa devem buscar relacionar a técnica de espectroscopia de energia dispersiva de raios$\mathrm{X}$ acoplada ao microscópio eletrônico de varredura no controle de qualidade da indústria de lácteos, bem como no 
desenvolvimento de novos produtos e na solução de problemas tecnológicos, em associação com técnicas usualmente empregadas nas indústrias.

\section{Agradecimentos}

À Universidade Federal de Juiz de Fora (Departamento de Química e Faculdade de Farmácia) e ao Conselho Nacional de Desenvolvimento Científico e Tecnológico (CNPq) pelas bolsas de produtividade 307334/2020-1 e 315337/2018-4.

\section{Referências}

Daly, K., Fenton, O., Ashekuzzaman, S. M., \& Fenelon, A. (2019). Characterisation of dairy processing sludge using energy dispersive X-ray fluorescence spectroscopy. Process Safety and Environmental Protection, 127, 206-210.

Damodaran, S., Parkin, K. L., \& Fennema, O. R. (2010). Química de Alimentos de Fennema. Artmed.

Dedavid, B. A., Gomes, C. I., Machado, G. (2007). Microscopia Eletrônica de Varredura - Aplicações e preparação de amostras: materiais poliméricos, metálicos e semicondutores. EDIPUCRS.

Deng, Y., Man, C., Fan, Y., Wang, Z., Li, L., Ren, H., Cheng, W., \& Jiang, Y. (2015). Preparation of elemental selenium-enriched fermented milk by newly isolated Lactobacillus brevis from kefir grains. International Dairy Journal, 44, 31-36.

Duarte, L. C., et al. (2003). Aplicações de Microscopia Eletrônica de Varredura (MEV) e Sistema de Energia Dispersiva (EDS) no Estudo de Gemas: exemplos brasileiros. Pesquisas em Geociências, 30(2), 3-15.

Espindola, W. R., Nascente, E. de P., Urzêda, M., Teodoro, J. V. da S., Gonçalves, G. B., Castro, R. D. de, Martins, M. E. P., \& Souza, W. J. de. (2020). Quality of refrigerated raw milk produced in the microregion of Pires do Rio, Goiás, Brazil. Research, Society and Development, 9(7), e153973958. https://doi.org/10.33448/rsd-v9i7.3958

Ferrer-Eres, M. A. et al. (2010). Archaeopolymetallurgical study of materials from an Iberian culture site in Spain by scanning electron microscopy with X-ray microanalysis, chemometrics and image analysis. Microchemical Journal, 95, 298-305.

Gandhi, G., Amamcharla, J. K., \& Boyle, D. (2017). Effect of milk protein concentrate (MPC80) quality on susceptibility to fouling during thermal processing. LWT - Food Science and Technology, 81, 170-179.

Goldstein, J., Newbury, D.E., Echlin, P., Joy, D.C., Lyman, C.E., Lifshin, E., Linda Sawyer, L., Michael, J.R., (2003). Scanning Electron Microscopy and Xray Microanalysis. Plenum Press.

Hussain, I., Bell, A. E., \& Grandison, A. S. (2013). Mozzarella-Type Curd Made from Buffalo, Cows' and Ultrafiltered Cows’ Milk: 2. Physicochemical Properties, Curd Yield and Quality, Casein Fractions and Micelle Size. Food and Bioprocess Technology, 6(7), 1741-1748.

Ismail, A. F., Khulbe, K. C., Matsuura, T., Ismail, A. F., Khulbe, K. C., \& Matsuura, T. (2019). RO membrane characterization. Reverse Osmosis; Elsevier: Amsterdam, The Netherlands, 57-90.

Jesus, E. L. de, Berndt, F. M., Meneguelli, M., \& Muniz, I. M. (2020). Physical chemical characteristics of cooled raw milk under federal inspection. Research, Society and Development, 9(3), e64932302. https://doi.org/10.33448/rsd-v9i3.2302

Kenneth P. Severin. (2004). Dispersive Spectrometry of Common Rock. https://link-springer-com.pbidi.unam.mx:2443/content/pdf/10.1007\%2F978-1-40202841-0.pdf

Kim, E. H. J., Chen, X. D., \& Pearce, D. (2009). Surface composition of industrial spray-dried milk powders. 2. Effects of spray drying conditions on the surface composition. Journal of Food Engineering, 94(2), 169-181.

Lima, E. de A., Botteon, R. de C. C. M., Baroni, F. de A., \& Lima, A. C. P. (2020). Influence of filamentous fungi and yeasts on bacterial count and somatic cells in samples of raw bovine milk. Research, Society and Development, 9(7), e304974135. https://doi.org/10.33448/rsd-v9i7.4135

Materials Evaluation and Engineering, Inc. (2016). Energy Dispersive x-ray Spectroscopy (EDS). Handbook of Analytical Methods for Materials, 15-16.

Murrieta-Pazos, I., Gaiani, C., Galet, L., Calvet, R., Cuq, B, \& Scher, J. (2012). Food powders: Surface and form characterization revisited. Journal of Food Engineering, 112, 1-21.

Manske, G. A., Danieli, B., Zuffo, G. R., Rigo, E., Gomes, F. J., Zampar, A., \& Schogor, A. L. B. (2020). Occurrence of Unstable non-acid milk (UNAM) on commercial farms in the extreme west of Santa Catarina. Research, Society and Development, 9(7), e715974654. https://doi.org/10.33448/rsd-v9i7.4654

Murrieta-Pazos, I., Gaiani, C., Galet, L. \& Scher, J. (2012). Composition gradient from surface to core in dairy powders: Agglomeration effect. Food Hydrocolloids, 26, 149-158.

Murrieta-Pazos, I., Galet, L., Rolland, C., Scher, J., \& Gaiani, C. (2013). Interest of energy dispersive X-ray microanalysis to characterize the surface composition of milk powder particles. Colloids and Surfaces B: Biointerfaces, 111, 242-251. 
Research, Society and Development, v. 10, n. 10, e262101018622, 2021

(CC BY 4.0) | ISSN 2525-3409 | DOI: http://dx.doi.org/10.33448/rsd-v10i10.18622

Oliveira, F. C. S. de, Farias, L. C. B., Carmo, R. M. do, Oliveira, L. A. de, Santos, G. de O., Silva, M. S., Leão, P. V. T., Cunha, J. V. T. da, Medeiros, J. S., Nicolau, E. S., \& Silva, M. A. P. da. (2020). Physico-chemical and sensory characteristics of fresh cheeses fermented with Milk kefir and water kefir. Research, Society and Development, 9(4), e153943015. https://doi.org/10.33448/rsd-v9i4.3015

Parween, R. et al. (2016). Elemental Analysis of Cow's Milk Applying SEM-EDX Spectroscopy Technique. FUUAST Journal of Biology, 6(2), $161-164$.

Pattaro, L., Silva, J. A. G. e, Farias, L. C. B., Medeiros, J. S., Teixeira, P. C., Cunha, J. V. T. da, More, J. C. R. S., Almeida, T. V. de, Nicolau, E. S., \& Silva, M. A. P. da. (2020). Physico-chemical and sensory analyzes of milk smoothies of diferente species fermented by kefir, flavored with banana and apple. Research, Society and Development, 9(5), e112953145. https://doi.org/10.33448/rsd-v9i5.3145

Pereira, A. S., Shitsuka, D. M., Parreira, F. J., \& Shitsuka, R. (2018). Metodologia da pesquisa científica. UFSM.

Siegbahn, K. et al. (1967). ESCA: Atomic, Molecular and Solid State Structure Studied by means of Electron Spectroscopy, Uppsala: Almquist \& Wiksells.

Scoutaris, N. et al. (2014). SEM/EDX and confocal Raman microscopy as complementary tools for the characterization of pharmaceutical tablets. International Journal of Pharmaceutics, 470, 88-98.

Toledo, P. H. D. M., Pereira, J. P. F., Perrone, Í. T., Carvalho, A. F., Oliveira, L. F. C., \& Stephani, R. (2020). Caracterização da superfície de partículas de produtos lácteos desidratados. Revista do Instituto de Laticínios Cândido Tostes, 75(1), 10-21. 